\title{
Contribuições da teoria antropológica do didático na formação de professores de matemática
}

Contributions of the anthropological theory of teaching in mathematics teacher training

Cintia Melo dos Santos ${ }^{1}$

José Luiz Magalhães de Freitas ${ }^{2}$

\section{Resumo}

No presente artigo, composto de duas partes, trazemos algumas discussões e resultados de pesquisas sobre como a Teoria Antropológica do Didático (TAD) tem contribuído para estudos desenvolvidos no âmbito da formação de professores. Na primeira parte trazemos uma discussão teórica da TAD e alguns resultados de uma pesquisa de mestrado que investigou aspectos didáticos e matemáticos valorizados por uma professora indígena de matemática ao ensinar geometria plana e espacial a uma turma do $3^{\circ}$ ano do ensino médio, em uma escola indígena da rede estadual do município de Dourados, em Mato Grosso do Sul. Na segunda parte realizamos uma discussão em torno do Percurso de Estudos e Pesquisas (PEP) ${ }^{3}$ como proposta metodológica para a formação continuada de professores de matemática, discussão está constituída de esboços iniciais de uma pesquisa doutoral em andamento.

Palavras chave: Percurso de Estudos e Pesquisas; Formação de Professores; Ensino de Geometria.

\section{Abstract}

This two-part article discusses and reports the findings of investigations on the contributions of Chevallard's Anthropological Theory of the Didactic (TAD) to studies conducted in the setting of teacher training. TAD is theoretically discussed in the first part, which also describes the findings of a master's research focused on didactic and mathematical aspects valued by an indigenous teacher of mathematics while teaching plane and spatial geometry to senior secondary students attending a public indigenous school in Dourados county, Mato Grosso do Sul state, Midwest Brazil. In the second part, a theoretical discussiondrawing on preliminary notes from an ongoing doctoral investigation-addresses the use of Chevallard's Study and Research Pathway (SRP) as a methodological approach to the continuing education of mathematics teachers.

\footnotetext{
${ }^{1}$ Universidade Federal da Grande Dourados | cintiamelos@hotmail.com

2 Universidade Federal de Mato Grosso do Sul | joseluizufms2@gmail.com

${ }^{3}$ Apesar de (CHEVALLARD, 2009) ter usado a sigla PER como a abreviação em francês de "Parcours d'Étude et de Recherche", nós optamos por usar PEP, que é a abreviação em português de "Percurso de Estudo e Pesquisa". Vale ressaltar ainda, que a sigla não foi legitimada como PER, na Espanha, por exemplo, denota-se por REI "Recorrido de Estudio e Investigación"
} 
Keywords: Study and Research Pathway; Professional Education of Teachers; Geometry Teaching.

\section{Introdução}

É fato que a nossa sociedade, constante mudança, encontra-se cada vez mais diversificada, participativa, solidária e integradora, disso resultando uma multiplicidade no modo como os alunos estão construindo seu próprio conhecimento. O papel da instituição escolar é criar e manter um ambiente social que possibilite ao aluno relacionar-se com o outro e com o conhecimento, visando a formação e inserção, na sociedade, de cidadãos bem informados e críticos, que saibam compreender o mundo em que vivem e nele atuar.

O professor é protagonista nesse contexto, devendo preparar e promover aulas que despertem o interesse do educando, que agucem sua curiosidade com temáticas e materiais didáticos que the sejam atraentes. Acreditamos que a formação continuada seja um caminho necessário para que isso ocorra de fato. Ao pensarmos sobre a formação continuada, vemos a possibilidade de desenvolver ações de formação orientadas por meio de reflexões compartilhadas que possam contribuir com estudos de situações problemáticas que tangem o ensino e aprendizagem de conteúdos matemáticos trabalhados em sala de aula.

Na matemática, o termo "didático" não se resume apenas ao estudo de práticas de ensinar e aprender conteúdos, resultante da relação entre professor e aluno em sala de aula. Segundo Chevallard, Bosch e Gascón (2001, p. 39) "a didática da matemática é a ciência que estuda os processos didáticos, os processos de estudo de questões matemáticas".

As pesquisas em didática da matemática, no entanto, não se limitam em compreender os processos didáticos desenvolvidos em sala de aula, mas visam elucidar o que é um processo de estudo, para posteriormente se voltarem às dificuldades que professores e alunos encontram para ensinar e aprender matemática. A Teoria Antropológica do Didático (TAD) possibilita estudar a matemática desenvolvida no conjunto de atividades humanas e de instituições sociais. Segundo Bosch e Chevallard (1999, p. 4) "a didática da matemática no campo da antropologia do conhecimento (ou antropologia cognitiva) considera que o ponto de partida continua intocável: tudo é objeto". Podemos listar como tipos de objetos as instituições e os indivíduos como sujeitos dessas instituições, lembrando que um objeto existe, segundo Bosch e Chevallard (1999, p. 8), "a partir do momento que existem instituições e pessoas que cultivam relações com esse objeto".

$\mathrm{Na} T A D$, considera-se que o livro é uma instituição, dependendo do entorno da pesquisa; uma pessoa também pode ser caracterizada como uma instituição; o mesmo ocorre com um determinado ano escolar. O termo "antropológico", nessa nomenclatura, admite como princípio fundamental que toda atividade humana pode ser descrita por meio de praxeologias: "toda atividade humana regularmente realizada pode descrever-se como um modelo único, que se resume aqui com a palavra praxeologia" (CHEVALLARD, 1998, p. 1).

A palavra "praxeologia" provém de dois radicais: praxis, que significa "prática", e logos, que significa "estudo". Assim, a praxeologia é o estudo da prática. Nesse sentido, essa teoria possibilita ao pesquisador investigar a matemática mobilizada e valorizada em práticas 
docentes e em livros didáticos. A praxeologia $[T / \tau / \theta / \Theta]$ se compõe dos seguintes elementos: tipo de tarefas $(T)$, técnica $(\tau)$, tecnologia $(\Theta)$ e teoria $(\Theta)$, ou seja, as atividades humanas fundamentam-se em realizar uma tarefa $t$ de certo tipo $T$, por meio de uma técnica $\tau$, amparada por uma tecnologia $\theta$, que se justifica por uma teoria $\Theta$.

A TAD possibilita investigar as práticas docentes por meio da praxeologia. Para tanto, são necessárias as seguintes atividades: observar, descrever e analisar os aspectos didáticos e matemáticos. Por conseguinte, é necessário entender a matemática realizada em sala de aula em torno de um tema estudado, que pode ser analisado por meio da Organização Matemática $(O M)$ - ou seja, identificar quais conteúdos são valorizados e edificados pelos professores em sua prática. A OM caracteriza o estudo do objeto matemático em um esboço praxeológico das atividades matemáticas, que podem ser descritas por meio das quatro componentes: tipo de tarefa $(T)$, técnica $(\tau)$, tecnologia $(\Theta)$ e teoria $(\Theta)$.

Referir-se a tipo de tarefas (T) significa dizer que existem tarefas $(t)$ que fazem parte desse grupo maior ( $\mathrm{T}$ ), ou seja, as tarefas (t) são mais particulares e o tipo de tarefas (T) abrange as várias tarefas que possuem técnicas comuns de resolução. As tarefas $(t)$ são expressas geralmente por um verbo que designa ação e está associado a um objeto. Como esclarece Chevallard (1998, p. 2), "calcular o valor de uma função num ponto é um tipo de tarefa, mas calcular, simplesmente, é o que chamamos de gênero de tarefas, que pede um determinado substantivo". Ao realizar um tipo de tarefas (T), existe uma "maneira de fazer", de como realizar essa tarefa $(\mathrm{t})$, denominada técnica - ou seja, para toda tarefa a ser cumprida existe uma técnica utilizada. Uma única técnica, no entanto, não é suficiente para realizar todas as tarefas contidas em um tipo de tarefas $(T)$, uma técnica não resolve todas as tarefas de determinado tipo, mas é possível que para um tipo de tarefa específica exista uma única técnica que a resolve. Cabe ressaltar que Chevallard (1998, p. 3) menciona que "a técnica não é necessariamente de natureza algorítmica".

A tecnologia $(\theta)$ tem como objetivo clarificar e explicar a técnica utilizada para realizar determinado tipo de tarefa ( $\mathrm{T}$ ) - ou seja, para qualquer tipo de tarefa $(\mathrm{T})$ existe uma técnica, justificada por uma tecnologia. Dependendo da instituição analisada, uma determinada técnica pode ser uma tecnologia $(\theta)$, embora em outra possa ser uma técnica, pois pode variar conforme o nível de escolaridade em torno da organização matemática (OM) analisada. Em determinado ano escolar, uma tecnologia $(\theta)$ que justifica a técnica utilizada pode, em outra etapa da aula ou em outro ano escolar, passar a ser uma técnica. Pode também ocorrer que a tecnologia esteja integrada à técnica, ou seja, a técnica é ao mesmo tempo uma tecnologia, pois se autojustifica. A teoria $(\Theta)$ é de natureza abstrata, podendo comparecer em uma instituição de forma explícita ou implícita; trata-se de demonstrações e outras provas, constituindo a justificação da tecnologia $(\theta)$, porém com rigor maior com relação à justificativa da tecnologia $(\theta)$ sobre a técnica, como menciona Chevallard (1998, p. 4): "Passa-se então a um nível superior de justificação-explicação-produção, o da teoria $(\Theta)$, que retoma, em relação à tecnologia, o papel que esta última tem com respeito à técnica".

Assim, no desenvolvimento da OM, o professor faz as suas escolhas sobre como introduzir o conteúdo, os conceitos valorizados e as atividades tidas como essenciais, entre outras escolhas, que são compreendidas por meio da Organização Didática (OD), ou seja, as escolhas metodológicas da forma de apresentação, ou da aula de matemática. Analogamente, Bosch e Gascón (2010) afirmam que toda organização praxeológica didática (OD), que vive em determinada instituição está apoiada e fortemente sustentada por um modelo epistemológico da matemática dominante naquela instituição. Logo, é necessário 
que a didática da matemática identifique e desenvolva modelos epistemológicos, para que possam surgir novas propostas de OD.

Desse modo, entender o ambiente escolar e as condições e restrições presentes na prática escolar é o início para desenvolver formações continuadas, entendendo-se primeiramente que o equipamento praxeológico matemático do professor não deve se resumir àquilo que ele deve ensinar. A OD pode ser estudada por meio da análise dos seis momentos didáticos ${ }^{4}$ propostos por Chevallard (1998), que ajudam a descrevê-la e possibilitam identificar aspectos priorizados pelo professor em diferentes momentos sobre sua prática em sala de aula.

Os momentos didáticos, segundo Chevallard (1998, p. 20), constituem "uma realidade funcional do estudo" e proporcionam ao professor uma análise de seus processos didáticos. Assim, em uma única OM podemos ter diferentes ODs, ou seja, o professor pode proceder didaticamente de forma diferenciada ao trabalhar com um mesmo conteúdo em salas diferentes. De modo geral, há práticas pedagógicas em que alguns momentos didáticos são mais valorizados.

A construção da OD por meio dos momentos de estudo, realizada pelo professor, tem por finalidade o ensino e a aprendizagem de uma OM. Para tanto, é necessário associar uma praxeologia a esse saber matemático. Para Chevallard, o saber matemático é um produto da ação humana em determinada instituição. Nesse sentido, a ecologia das tarefas permite compreender como o saber é vivenciado nessa instituição.

Gascón (2003) resume as organizações didáticas em um espaço tridimensional com os seguintes eixos: teoricista, tecnicista e modernista (Figura 1).

No eixo teoricista temos o bloco tecnológico-teórico $(\theta / \Theta)$, composto pelas tecnologias e teorias. Um modelo de prática pedagógica que prioriza o teoricismo compreende que aprender matemática significa aprender teorias, ou seja, realizar organizações dedutivas envolvendo definições, postulados, demonstrações, tautologias e outras provas. Um exemplo desse modelo é o proposto na obra clássica Os elementos, de Euclides, escrita por volta de 300 a.C. No eixo tecnicista, temos o bloco prático $(T, \tau)$, composto pelas tarefas e técnicas. A organização didática tecnicista compreende que aprender matemática resulta do trabalho com diversas tarefas e técnicas, ou seja, a aprendizagem ocorre por meio da repetição de vários exercícios do mesmo tipo, que conduzirão à memorização de regras e procedimentos.

\footnotetext{
4 o primeiro momento é o encontro com a organização matemática, que pode ocorrer de várias maneiras, como, por exemplo, quando o professor inicia um novo conteúdo apresentando conceitos e definições, ou por meio de algum tipo T de tarefa, partindo de uma situação problema para iniciar o conteúdo. O segundo momento é o da exploração do tipo de tarefa e da elaboração de uma técnica. O terceiro é o da constituição do ambiente tecnológico-teórico relativo à técnica. O quarto momento é dedicado ao trabalho com a técnica: tratase de testar e melhorar a técnica, verificando seu alcance e se resolve todas as tarefas $t$, para um tipo $T$ de tarefa, com o intuito de deixá-la mais eficaz e confiável. O quinto momento é o da institucionalização. Nesse momento, o professor define o que realmente o aluno deve saber sobre o conteúdo proposto depois de realizar as tarefas solicitadas. O sexto e último momento é o de avaliação, que se articula com o momento de institucionalização, porque o professor analisa a praxeologia com os alunos, bem como seus limites e possibilidades de utilização, podendo este sexto momento ocorrer ou não, a depender da escolha do professor.
} 


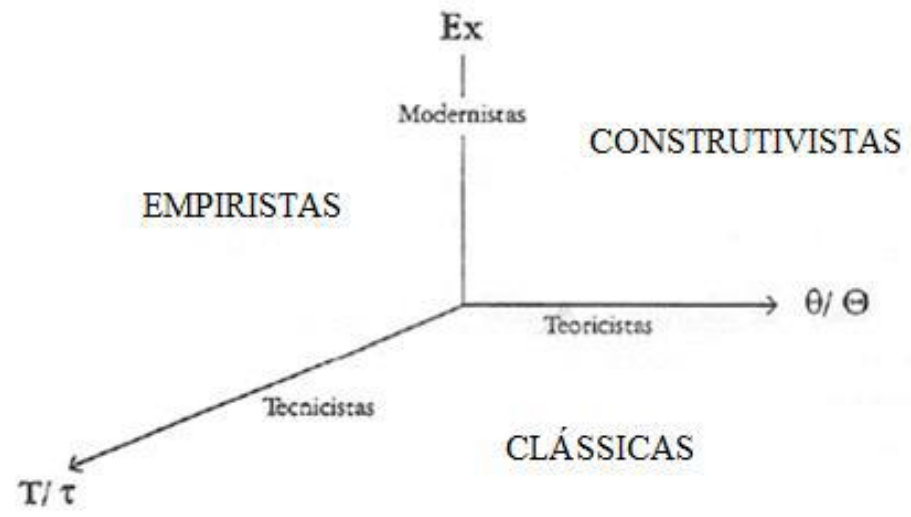

Figura 1. Modelo epistemológico de organizações didáticas (GASCÓN, 2003, p. 21).

Ambos os eixos, teoricista e tecnicista, compreendem um processo didático totalmente mecânico, considerando o aluno, respectivamente, como uma "caixa vazia" que aprende conforme as informações recebidas e o como um "autômata", que aprende mediante o domínio de técnicas repetitivas. O terceiro eixo, denominado modernista, é composto de experimentação. A prática valorizada nesse eixo está na exploração de problemas não triviais. Segundo Gascón, nessa prática aprende-se matemática mediante exploração (tentar técnicas diversas, aplicar algum resultado conhecido, buscar problemas semelhantes, formular conjecturas, buscar contraexemplos).

Ao combinar os momentos do bloco tecnológico-teórico $(\theta / \Theta)$ com os do bloco prático $(T, \tau)$ temos uma abordagem clássica, que considera que o processo de ensino é totalmente controlado pelo professor. Da combinação dos momentos do bloco prático ( $T$, $\tau)$ com a experimentação, temos a abordagem empirista, que considera que aprender matemática é um processo indutivo baseado em imitar o modelo proposto de atividade por meio de várias práticas. Da articulação entre a experimentação e a valorização do bloco tecnológico-teórico $(\Theta / \Theta)$, temos a abordagem construtivista, que se propõe a contextualizar a atividade, considerando que aprender matemática significa um processo ativo de construção do conhecimento.

Segundo Chevallard (2002) existe uma relação entre os dois tipos de organização (a OM e OD), que é definida conforme os níveis de codeterminação. Para estabelecer uma praxeologia relacionada com o saber matemático, esse saber deve estar relacionado a uma escala hierárquica, na qual cada nível corresponde a uma realidade e determina os nichos e hábitat das OMs e ODs, conforme aponta Chevallard (2002): Sociedade, Escola, Pedagogia, Disciplina, Domínio, Setor, Tema e Objeto.

Na pesquisa desenvolvida por Santos e Freitas $(2013)^{5}$, foram analisados aspectos matemáticos e didáticos mobilizados por uma professora indígena de matemática ao trabalhar o ensino de figuras planas e espaciais no $3 .^{\circ}$ ano do ensino médio. Investigaramse as condições e restrições desse saber na prática analisada, buscando compreender como o conhecimento matemático foi vivenciado nesta instituição. Assim, os níveis de codeterminação permitiram compreender as relações entre Sociedade (referencial curricular

\footnotetext{
${ }^{5}$ Pesquisa de mestrado intitulada Análise da prática pedagógica de uma professora indígena voltada para a geometria no ensino médio. Disponível em: <https://inma.ufms.br/ppgedumat/dissertacoes/>.
} 
do estado), Escola (educação escolar indígena), Pedagogia (interculturalidade e bilinguismo), Disciplina (matemática), Domínio (geometria plana e espacial), Setor (identificação e classificação de sólidos geométricos e cálculo de área de figuras planas), Tema (prismas e pirâmides) e Objeto (cálculo da área da superfície de um prisma). Nessa pesquisa, os níveis Sociedade, Escola e Pedagogia foram os níveis de codeterminação que mais direcionaram a prática da professora indígena, apesar de compreendermos que os níveis de codeterminação se relacionam tanto da Sociedade para o Objeto, quanto do Objeto para a Sociedade.

Para Chevallard (2009), a didática é a ciência das condições e restrições de difusão social - a partir de pessoas e de instituições - das praxeologias, e no decorrer da pesquisa observa-se o assujeitamento da professora às condições e restrições que pesam sobre as escolhas feitas por ela, ou seja, a OM a OD estão diretamente ligadas aos níveis de codeterminação - primeiramente, com relação à Sociedade (referencial curricular das escolas estaduais), ou seja, a professora ${ }^{6}$, tinha que direcionar sua prática em sala de aula a partir do conteúdo programático do referencial curricular estadual para todas as escolas da rede estadual de ensino e, além disso, em cada escola estadual existia uma coordenadora de matemática que, entre outras funções, acompanhava o cumprimento dos conteúdos pelos professores. Durante todas as preparações das aulas, a professora manifesta a necessidade de justificar todas as ações em sala de aula para a coordenadora de área, responsável pela disciplina de matemática. Segundo ela, quem define quanto (controlando o tempo de trabalho em sala de aula) do conteúdo deve ser trabalhado é a coordenação, no sentido de cobrança do cumprimento do currículo estadual.

Além desse nível de codeterminação que condiciona a prática da professora, expresso pela Sociedade, foi considerado outro nível de codeterminação que é o da Escola, que também tem condições e restrições influenciadas pela educação escolar indígena e pela Pedagogia (interculturalidade e bilinguismo). Nesse sentido, a escola busca atender as especificidades da escola indígena, por se tratar de uma comunidade em que estão presentes as etnias Guarani, Kaiowá e Terena, numa proposta que atenda um ensino bilíngue e intercultural, mas ao mesmo tempo se dispõe a cumprir um currículo proposto a todas as escolas estaduais sul-mato-grossenses. A educação escolar indígena apresenta uma proposta curricular específica, que não se verifica na escola pesquisada, sendo que tais relações intervêm diretamente na OM e na OD valorizadas pela professora - ou seja, nos níveis de codeterminação que expressam condições e restrições na sala de aula. Nesse sentido, não foi observada nenhuma ementa específica para o ensino de matemática nessa escola.

Para Chevallard (2009), para uma determinada pessoa ou instituição tudo é, em princípio, condição - e uma condição também pode ser uma restrição. Nesse caso, uma restrição é constituída de condições que não podem ser modificadas. Logo, na pesquisa desenvolvida por Santos e Freitas (2013), a prática desenvolvida pela professora, apesar da discussão e do diálogo com os pesquisadores na preparação de suas as aulas (relacionando Domínio, Setor, Tema e Objeto), mantém a apresentação dos conteúdos um após o outro, sem se referir aos Setores e Domínios, trabalhando de uma forma que Chevallard (2002) denomina como fila indiana. Identificamos assim um distanciamento com relação ao

\footnotetext{
${ }^{6}$ Neste artigo, designaremos a professora indígena simplesmente como professora.
} 
discurso e à prática da professora, visto que, em vários encontros de planejamento, ela manifestou intenção de realizar uma metodologia diferente daquela com que estava habituada, mas que resultou em condições não modificadas, ou seja, em restrições em sua prática pedagógica.

Considerando os encontros de planejamento e a observação em sala de aula, constatamos que em suas aulas a professora demonstrou uma postura predominantemente tecnicista, que, conforme Bosch e Gascón (2010), é a de que ensinar é apresentar modelos para serem seguidos, proporcionando poucas oportunidades de reflexão ou de experimentação pelos alunos sobre o que se trabalha em sala de aula e dando pouco valor aos momentos teórico-tecnológicos. Desse modo, a OM e a OD da professora estão pautadas numa organização didática clássica, com tendência a se aproximar da abordagem tecnicista, com mínimos aspectos teórico-tecnológicos. Essa caracterização deve-se, certamente, à insegurança quanto a seus conhecimentos sobre conteúdos geométricos e também à imposição da escola em cumprir o currículo estadual, bem como à dificuldade de trabalhar em uma perspectiva intercultural, permanecendo no plano das intenções. Constatamos, assim, que, embora a instituição escolar se localize numa aldeia indígena, as condições e restrições em nível da escola se mostraram determinantes nas escolhas matemáticas e didáticas da professora.

$\mathrm{Na}$ condução de suas aulas, a professora expressou grande insegurança quanto ao conteúdo proposto, apoiando-se nos conceitos apresentados nos livros didáticos e em pesquisas realizadas na internet, também devido ao tempo escasso que possui para planejar. Por outro lado, ela expressa que se apossou dos encontros de planejamento para as aulas, como oportunidade de estudo. Pôde-se porém concluir que o tempo de planejamento dedicado ao estudo dos conteúdos propostos em sala de aula foi insuficiente, o que contribuiu para a insegurança da professora.

A pesquisa levou os autores a sentir necessidade de proporcionar aos professores mais espaços de estudo e pesquisa em torno da OM e da OD, colaborando ideias de Chevallard (2012) quanto à necessidade de mudança de paradigmas. Para esse autor, existem os paradigmas denominados "velhos", que se organizam em torno de doutrinas e sistemas da matemática, em que o conhecimento é fragmentado e que são trabalhados como "visitas de trabalho" ou "visitas a monumento". Visitar um monumento basicamente resume-se em ver um relatório ou uma história feita pelo professor, que guia o aluno sobre o monumento visitado. Por exemplo, a fórmula de Heron para a área de um triângulo é abordada como um monumento que fica sobre si mesmo. Os estudantes são meros espectadores e todo o conhecimento ensinado pode ser esquecido ou, mais exatamente, ignorado, assim que as provas se encerrarem.

Para Chevallard, a didática é uma dimensão vital das sociedades humanas. Uma pessoa faz algo, ou até mesmo manifesta a intenção de fazê-lo, para que alguém possa "estudar" ou "aprender" algo. Esta alguma coisa a ser estudada (e aprendida) é conhecida como o jogo da didática nessa situação. Desse modo, o autor refere-se a um terceto didático $(X, Y$, $O)$, onde $X$ e $Y$ representam um conjunto de pessoas e $O$ refere-se ao objeto didático estudado. A didática da matemática está relacionada com casos em que o jogo didático $\bigcirc$ refere-se e pertence à matemática. Assim, os paradigmas didáticos são os jogos didáticos $\bigcirc$ e as formas de estudar esses jogos didáticos.

Nesse sentido, Chevallard (2012) analisa um novo paradigma didático, o paradigma "questionar o mundo", que se baseia grandemente em quatro conceitos inter-relacionados, 
que são o da "inquisição", o do ser "herbartiano", o "procognitivo" e o "exotérico". Nesse novo paradigma, Chevallard (2012) menciona que a educação é um processo longo, e que deve ser trabalhado com pessoas em diferentes idades. Nesse sentido, o $X$ no terceto $(X, Y$, O) pode ser uma criança, bem como um adulto maduro ou uma pessoa mais velha. Assim, no novo paradigma é importante avaliar como as pessoas do atual momento e os futuros cidadãos estão aprendendo e como isso está acontecendo.

Um segundo princípio desse novo paradigma considera que para aprender algo sobre algum trabalho $\mathrm{O}, \mathrm{X}$ tem que estudar sobre $\mathrm{O}$, muitas vezes com a ajuda de algum $Y$. Logo, para aprender a resolver uma equação cúbica, a pessoa não aprende pela sorte; é preciso parar e considerar a questão proposta, ou seja, X não é obrigado a saber tudo sobre situações que envolvem os problemas da situação que ele nunca conheceu ou nunca solucionou. Assim, no paradigma "questionar o mundo", quer-se que o futuro cidadão se torne um ser herbatiano - termo que faz referência ao filósofo alemão e fundador da pedagogia Johann Friedrich Herbart (1776-1841), referindo-se à atitude receptiva com relação a questões não respondidas e problemas não resolvidos, que é normalmente a atitude do cientista em seu campo de pesquisa e que deve tornar-se atividade de todo cidadão.

Por outro lado, o paradigma "questionar o mundo" exige uma atitude muito distinta, uma atitude procognitiva, no sentido de que a pessoa busca comportar-se como se o conhecimento fosse algo essencialmente a ser descoberto e ainda conquistado - ou seja, há possibilidades de redescobrir e conquistar coisas novas.

O paradigma de questionar o mundo, encontrar novos conhecimentos ou reencontrar os velhos torna possível um longo caminho de pesquisa, um caminho de estudo, que são os meios pelos quais o orientador ou pesquisador aprendem e reaprendem. Nesse contexto, os conteúdos aprendidos não são planejados com antecedência: ao contrário do que é habitual no paradigma de visitar monumentos, nesse novo paradigma o conteúdo é determinado por dois fatores: pela pergunta $Q$ a ser estudada, no primeiro momento, e em seguida pela pesquisa e caminho de estudo percorrido para a solução da pergunta $Q$, sendo que no decorrer desse trajeto surgem mais questões a partir da pergunta geradora Q.

Desse modo, o novo currículo, sob o paradigma "questionar o mundo", dependerá de oferecer ferramentas para inquirir ou fazer perguntas sobre questões geradas pelo currículo. Isso não mais dependerá de qualquer hierarquia estabelecida ou das disciplinas. Qualquer questão Q pode ser suplementada significativamente por uma ou uma série de "questões derivadas" $Q^{*}$, que constituirão o critério para controlar a qualidade e a profundidade das perguntas na questão $\mathrm{Q}$.

Nessa perspectiva, o PEP propõe que por meio de uma questão, ou um conceito, conteúdo ou área, se possam realizar estudos em torno do objeto a ser pesquisado, pensando que, conforme o milieu (o meio, M) as praxeologias apresentam condições e restrições - ou seja, em vez de propor um planejamento rígido de atividades, cabe pensar nas escolhas priorizadas a partir do contexto da situação, como afirma Chevallard:

Uma questão $Q$ chama uma investigação, que se realiza em um certo percurso de estudo e de pesquisa. Uma mesma questão $Q$ pode conduzir uma classe a reencontrar um complexo de obras que podem variar dependendo do percurso tomado (o que depende da atividade de $X$, das decisões de $Y$, mas também dos recursos praxeológicos $R_{i}^{\diamond}$ e $O_{i}$ atualmente acessíveis. (CHEVALLARD, 2009, p. 28) 
O PEP tem início com uma questão Q0, denominada de questão geratriz, que evolui surgindo novas questões: Q1, Q2, Q3, ...Qn. O estudo da questão Q0 e suas questões derivadas, conduz a um percurso de estudo em busca de respostas a essas questões, constituindo (Qi, Ri) o conjunto de questões e respostas de Q0. Desse modo, o sistema didático $[S(X, Y, Q) \rightarrow M] \rightarrow R$ reproduzirá o $M$ (meio) a ser utilizado para desenvolver a resposta $R$. O expoente sobre $R \bullet$ indica que a resposta para $Q$ foi produzida sob determinadas restrições e que $M$ é composto das diferentes respostas encontradas no decorrer do estudo, e das obras que permitiram a construção dessas respostas. Logo, $M=$ $\{R 1, R 2, \ldots, R n, O n+1, . ., O m\}$.

Nesse viés, a questão $Q_{0}$ impulsiona a busca de novas questões, e diferentes respostas provisórias que impulsionam uma nova modelização matemática, em busca da resposta $\mathrm{R}^{*}$, sendo a questão $Q_{0}$ a que assegura a veracidade do percurso. Para ilustração do PEP, podemos propor a seguinte questão, em torno de conceitos geométricos:

Q: Como os livros didáticos apresentam a noção de polígono ${ }^{7}$ ? Foram identificadas algumas definições de polígono apresentadas em diferentes livros didáticos. As três primeiras definições foram encontradas em livros voltados ao 6. ${ }^{\circ}$ ano do ensino fundamental e a quarta definição provém de um livro destinado ao ensino superior.

Definição 1 - Uma linha poligonal fechada e simples com sua região interna forma um polígono (Matemática, Departamento de Edições Educativas, São Paulo, Moderna, 2004). Observação: o autor define que uma linha do plano é chamada poligonal se for formada apenas por segmentos de reta, de maneira que os segmentos consecutivos são não colineares.

Definição 2 - Um polígono é uma figura geométrica plana com contornos retilíneos (Imenes \& Lellis, Matemática, São Paulo, Scipione, 2001).

Definição 3 - Polígonos são figuras que têm seu contorno formado apenas por segmentos de retas (Bianchini \& Miani, Construindo conhecimento em matemática, São Paulo, Moderna, 2000).

Definição 4 - Seja $A_{1}, A_{2}, A_{3}, \ldots, A_{n}, n \geq 3$, uma sequência de $n$ pontos distintos tais que os segmentos $A_{1} A_{2}, A_{2} A_{3}, \ldots, A_{n} A_{1}$ têm as seguintes propriedades:

1. Nenhum par de segmentos se intersecciona a não ser em suas extremidades.

2. Nenhum par de segmentos com extremidade comum está na mesma reta.

Um polígono é o conjunto formado dos pontos do plano pertencentes ao conjunto $A_{1} A_{2} \cup A_{2} A_{3} \cup \ldots \cup A_{n} A_{1}$. Apresente exemplos de figuras que satisfazem uma definição, mas não a outra (ou outras), sempre justificando suas escolhas.

Buscando-se compreender a questão $Q_{0}$, podem surgir outras questões, tais como: $Q_{1}$ : Polígono é uma figura unidimensional? $Q_{2}$ : Polígono é uma figura bidimensional? $Q_{3}$ : Quais são os elementos (vértice, lados, ângulo) do polígono? Q4: O que é um polígono simples? $\mathrm{Q}_{5}$ : O que são um polígono convexo e um polígono côncavo? $\mathrm{Q}_{6}$ : O que é uma figura? $\mathrm{Q}_{7}$ : O que é uma superfície poligonal ou região poligonal? $Q_{8}$ : Como se calcula o perímetro de um polígono? Qg: O que é um polígono regular? $Q_{10}$ : Como determinar as diagonais de um polígono? $\mathrm{Q}_{11}$ : Como determinar a soma dos ângulos internos de um polígono convexo? $\mathrm{Q}_{12}$ : Como determinar a soma dos ângulos externos de um polígono convexo?

\footnotetext{
${ }^{7}$ Questão desenvolvida com um grupo de professores da Educação Básica, na pesquisa de doutorado em andamento no PPGEDumat.
} 
Assim, ao se trabalhar com o PEP, podemos ter o estudo de atividades já previamente conhecidas de $[X, Y]$ que necessitam de um aprofundamento ou, ainda, atividades desconhecidas de $[X, Y]$, que o PEP deve levar $X$ a conhecer. No exemplo apresentado, podemos inferir que a questão $Q_{0}$ possibilitará a $X$ (re)construir diferentes conceitos geométricos essenciais à compreensão de outros conteúdos no campo da geometria e para outros campos da matemática.

Nesse sentido, o caráter implicitamente fantasiado é o que o autor chama de exotérico (usando o assim o adjetivo também como um substantivo), ou seja, as pessoas assumem que já têm todo o conhecimento necessário sobre determinada área. Por outro lado, um exotérico tem que estudar e aprender indefinidamente, e nunca atingirá o estado ilusório de exotérico. Assim, todos os verdadeiros estudantes são exotéricos a fim de permanecerem estudiosos: exotericismo, como o autor propõe, é uma fábula.

O paradigma "questionar o mundo" deve ser base na sociedade e na escola, e devemos reviver o espírito da matemática. Assim, segundo Chevallard (2009), trabalhar coletivamente sobre praxeologias permite aos professores discutirem como acontece o processo de ensino e aprendizagem de determinado conceito e é ferramenta essencial para combater o ensino rotineiro em sala de aula:

A "metodologia", portanto, é o que eu chamarei as praxeologias de pesquisa colocadas em jogo em um determinado campo (ou em uma dada pesquisa particular). Eu aproveito este momento para enfatizar que o trabalho coletivo sobre as praxeologias de pesquisa em didática, ou seja, sobre "os métodos e procedimentos pelos quais tal conhecimento e compreensão são alcançados" e "a formulação de métodos sistemáticos e logicamente consistentes para a busca de conhecimento", me parece hoje mais necessário do que nunca, para combater os efeitos da rotina ou mesmo da quase naturalização dos métodos frequentemente utilizados. (CHEVALLARD, 2009, p. 11)

Para Ruiz (2015), a estrutura de um PEP está sempre aberta e indeterminada em seu início, uma vez que é o processo em si que vai delinear as formas possíveis para o percurso (com muitos contratempos, desvios e atalhos, conforme necessário) e, ainda, ao logo do $P E P$, a questão geradora $Q$ evolui e se transforma em uma ou mais questões novas. Para essa autora, a noção de PEP surge da necessidade de ter organizações educacionais, como a escola e qualquer outra instituição, numa epistemologia verdadeiramente funcional, que aparecem como máquinas de produção de conhecimento útil para a criação de respostas $\mathrm{R}$ a perguntas $\mathrm{Q}$.

Na pesquisa desenvolvida por Lucas (2015), foi desenvolvido um PEP com alunos de um curso de medicina nuclear, visando alcançar uma possível razão de ser do cálculo diferencial elementar. Para essa autora, o PEP é constituído primeiramente por um modelo epistemológico dominante (MED), que é verificado por meio de análise de livro didático e dos referenciais prescritos. A partir dessas análises, o pesquisador verifica desarticulações entre as tarefas e técnicas desenvolvidas em torno de determinado conteúdo ou, ainda, que as praxeologias apresentadas não permitem uma construção de praxeologias com um nível de complexidade crescente. Assim, o pesquisador terá necessidade de desenvolver um modelo epistemológico de referência (MER) em torno do conteúdo analisado. Logo, por meio de experiências pessoais do professor, de pesquisas relacionadas ao tema e de livros 
didáticos, paradidáticos, entre outros recursos, o professor constrói um MER, um estudo aprofundado sobre o conteúdo.

Assim, o MER serve para a elaboração de novas propostas de OD, desenvolvidas por meio do PEP. No entanto, esses modelos devem ser considerados como sistemas de referência relativos e provisórios para o pesquisador, pois, como expõem Bosch e Gascón (2010, p. 7), "a teoria da transposição didática nos ensina que não há nenhum sistema de referência privilegiado para analisar as diferentes etapas da transposição didática".

Para Andrade (2012), o PEP:

[...] se constitui em um Percurso de Formação de Professores, na formação inicial e continuada, à medida que vem constituir processos de estudos para o enfrentamento do problema praxeológico da instituição docente, de questões que emanam das e nas práticas docentes, das condições e restrições impostas a essas problemáticas, eliminando riscos de se querer formar professores a partir de um EP imutável que se deixaria sob a responsabilidade do professor para mobilizá-lo em situações concretas. (p. 36)

Nesse sentido, estamos iniciando uma pesquisa de doutorado com o objetivo de investigar e analisar as contribuições do PEP enquanto proposta metodológica para a formação continuada de professores. Para tanto, alguns questionamentos emergem: Como iniciar um PEP? Como pensar em um PEP para formação de professores? O que faz a formação continuada ser considerada um PEP? Quais pesquisas trabalham com o PEP para a formação de professores?

Diante de tais questionamentos, delimitamos primeiramente o conteúdo matemático a ser estudado, dando continuidade à pesquisa de Santos e Freitas (2013), com foco no estudo dos conteúdos geométricos.

Desse modo, ao falarmos do ensino da geometria proposta nos currículos nacionais, não podemos deixar de mencionar o papel do professor em todo esse contexto. Como os professores concebem o ensino de geometria? De que conhecimentos dispõem quando vão ensinar? Mediante essas indagações começamos a refletir sobre a importância que o ensino da geometria tem na formação do professor de matemática.

Algumas pesquisas (PAVANELLO, 1993; LORENZATO, 1995; LINDQUIST, 1994) apontam haver no ensino de geometria evidências de uma defasagem diretamente ligada à prática do professor em sala de aula, como deixar de ensinar conceitos geométricos por não compreender os conceitos a serem propostos aos alunos. Poderíamos ainda afirmar, concordando com esses pesquisadores, que o professor deixa, em grande parte, de ensinar conceitos geométricos por não os compreender? Tais realidades, pesquisadas há mais de 20 anos, parecem não haver direcionamentos muito diferentes dos mais recentes. Como aponta Leivas (2012), há muito o que fazer na formação do professor de matemática que atuará na educação básica brasileira, com relação ao ensino de geometria, e destaca:

Em uma pesquisa com oito Cursos de Licenciatura em Matemática do RS, verificou-se que todos eles oferecem um semestre de Geometria Plana e um semestre de Geometria Espacial, geralmente desenvolvidos de forma axiomática. Não há indicativos de que a disciplina de Geometria Analítica seja desenvolvida de outra forma, a não ser priorizando a Álgebra em detrimento da Geometria, ou seja, são os algoritmos em primeiro lugar, os 
quais enquadram determinadas expressões algébricas nessa ou naquela figura geométrica. (LEIVAS, 2012, p. 10)

Para Leivas (2012), a condução do ensino de geometria deve perpassar três conceitos que julga necessários para o desenvolvimento do pensamento geométrico: imaginação, intuição e visualização. Nos cursos de matemática, não se percebeu qualquer indicativo de que esses elementos norteadores para o ensino de geometria fossem trabalhados. Para esse autor, é fundamental que no ensino de geometria se caracterize também o conhecimento matemático, trabalhando-se com conceitos, propriedades geométricas e demonstrações, ou seja, adotando-se uma abordagem tanto dedutiva quanto experimental, sem priorizar uma delas.

Para Pais (2006), o ensino de geometria deve ser intermediado por meio de quatro elementos: objetos, conceitos, desenhos e imagens mentais. Quando o professor realiza essas articulações, permite que o trabalho didático resulte na construção do conhecimento geométrico pelo aluno, porque:

A aprendizagem da geometria recebe influência de três aspectos que devem ser considerados na condução da prática educativa: intuição, experiência e teoria. O significado do saber escolar pode ser ampliado através das articulações entre esses aspectos mediados pela linguagem, pelo uso de objetos materiais e por desenhos, visando à formação de imagens mentais associadas aos conceitos. (PAIS, 2006, p. 93)

Almouloud et al. (2004) atribuem o fracasso do trabalho com conteúdos geométricos à "má" formação do professor - ou seja, a formação inicial não propicia reflexão mais profunda sobre o ensino e aprendizagem dessa área da matemática, e a formação continuada não atende os objetivos esperados em relação à geometria. A pesquisa destaca também as dificuldades no próprio sistema educativo, que deixa a cargo da escola definir os conteúdos que julgue importantes para a formação de seus alunos e os problemas geométricos propostos pelos livros didáticos que privilegiam resoluções algébricas, poucos dos quais exigem raciocínio dedutivo ou demonstração.

Para Nunes (2010) é importante que o professor vivencie situações e reflexões sobre o ensino de Geometria, tais vivências contribuem para a formação do seu próprio pensamento geométrico e ressalta:

É fato que professores, quando questionados a respeito do ensino de Geometria, solicitem cursos de extensão que priorizem reflexões de suas práticas pedagógicas, pois não se sentem preparados para trabalhar segundo as recomendações e orientações didáticas e pedagógicas dos PCNs. Falta-Ihes clareza sobre como ensinar Geometria e/ou acerca de habilidades que possam ser desenvolvidas nesse nível de ensino. (NUNES, 2010, p. 111)

Tais pesquisas nos propiciaram olhar para uma formação continuada, possibilitando pensar em formações guiadas por meio de processos investigativos que possam contribuir com as práticas pedagógicas que tangem o ensino de conceitos geométricos na educação básica. Diante desse quadro, optamos por criar um grupo de formação continuada com foco central na constituição de um PEP e investigar como esse PEP pode contribuir para a formação do professor de matemática em suas práticas em sala de aula. 
Ao pensarmos na formação de professores, assumimos a concepção de Mizukami (2002), que a vê como um processo contínuo, em desenvolvimento na vida toda, e cujo fio condutor é a reflexão. Logo, a presente pesquisa visa desencadear uma formação que leve os professores a refletir, discutir e analisar o ensino de geometria.

Para Perrenoud (2002), uma postura fundamental para o professor é a prática reflexiva, pois estamos em uma sociedade em transformação, e a capacidade de inovar, negociar e regular a prática é decisiva. Assim, acreditamos que, em um processo de formação, um meio de trocas de experiências favorece a construção de novos saberes, ou seja, um processo de formação propicia novos aprendizados que resultam da reflexão sobre a prática. Para Altet (2001, p. 26), a reflexão é desencadeada por um processo coletivo, por meio de relatos de experiência: "O professor profissional, é antes de tudo um profissional da articulação do processo de ensino-aprendizagem em uma determinada situação, um profissional da interação das significações partilhadas".

Explicita-se assim a importância da atuação coletiva dos professores em espaços que propiciem trocas reflexivas sobre as práticas, como complementa Mizukami (2002, p. 15): "A formação docente é, então, vista segundo modelo artístico e reflexivo, tendo por base a concepção construtivista da realidade com a qual o professor se defronta, entendendo que ele constrói o seu conhecimento de forma idiossincrática e processual".

Frente a essas considerações, surgem questionamentos quanto à formação continuada: Como conduzir uma formação que leve o professor a refletir sobre sua própria prática? Nesse sentido, encontramos em Chevallard (2009) o PEP, que propicia processos de produção coletiva que levam o professor à reflexão por meio de estudos e pesquisas de praxeologias em torno de determinado conteúdo. Outros questionamentos suscitados incluem: Quais são as praxeologias desenvolvidas pelos professores da educação básica? Quais influências, condições e restrições implicam diretamente no ensino de geometria em sala de aula?

Para a realização da pesquisa, desenvolvemos um projeto de extensão pela Universidade Federal da Grande Dourados (UFGD) intitulado "Formação continuada com professores da Educação Básica: um estudo dos conceitos geométricos", com o objetivo de realizar estudos referentes aos conteúdos geométricos trabalhados do $6 .^{\circ}$ ao $9 .^{\circ}$ ano do Ensino Fundamental e do Ensino Médio. Assim, optamos por desenvolver um PEP com esses professores visando fomentar discussões acerca dos conteúdos geométricos e estimular-lhes o pensamento crítico e reflexivo na elaboração e planejamento de suas aulas.

Adotando pressupostos do PEP, com o propósito de investigar e analisar suas contribuições e limitações enquanto proposta metodológica para a formação continuada de professores de matemática, trabalhamos com um grupo de seis professores, todos atuantes no ensino público dos anos finais do Ensino Fundamental, iniciando com um estudo sobre comparações de definições, tendo como ponto de partida o conceito de polígono. A questão Q0 apresentada anteriormente foi desenvolvida com esse grupo de professores visando identificar a existência ou não de divergências entre os conceitos, bem como para observar conhecimentos geométricos mobilizados por esses professores e o modo como são desenvolvidos esses conteúdos em sala de aula.

Ao trabalhar com a questão Q0, no decorrer do estudo, foram levantadas várias questões, dentre as quais destacamos: Q1: "[...] qual a definição de segmento de reta?"; Q2: 
"[...] o que é uma dimensão, o que significa duas dimensões?"; Q28: "[...] considera o preenchimento a região, ou só o contorno?"; Q3: "[...] todo polígono ele é considerado uma figura plana, mas eu não sei se toda a figura plana ela pode ser dita como um polígono?"; Q4: "O significado da palavra polígono não é vários ângulos?"; Q5: "[...] um polígono é uma figura geométrica plana. O que é uma figura geométrica plana?"; Q6: "[...] quando falo plano, já tenho a ideia de duas dimensões?"; Q7: "[...] quando vai dar o conceito de polígono, ela já tem o conceito do que é ângulo?"; Q8: "[...] polígono são figuras bidimensionais?"; Q9: "O que é figura?"; Q10: "[...] assumir ou não o dentro, eu estou tentando imaginar assim que quando a gente vai falar sobre perímetro e área, você fala área, você acostuma a falar assim, aquele que está dentro, não é?"

Sem dúvida a definição de polígono gerou muitas dúvidas entre os participantes da formação, pois ao considerar o polígono somente como seu contorno, quando dizem "a área do quadrado" não estariam se referindo à área de um quadrado, já que o quadrado consistiria somente no contorno: uma figura unidimensional. Os professores tiveram grande dificuldade e às vezes comentavam "eu achava que sabia ensinar Geometria", diziam ainda, "[...] essa atividade está desestabilizando a gente". Nas discussões sobre essas questões, geradas da questão Q0 do PEP, houve participantes que concordavam quando um colega justificava o porquê de uma definição e discordavam quando outro refutava a mesma justificativa. No final do encontro, viam-se concordando com tudo, já sem certeza de nada, revelando a necessidade de continuidade do PEP, o que vem sendo desenvolvido.

Certamente, O PEP se configura como procedimentos que podem propiciar aos professores a vivência de processos investigativos em torno de demandas de suas próprias OM e OD e constitui uma proposta para os professores na busca e valorização de outros momentos didáticos, bem como de outras práticas pedagógicas.

Em suma, os procedimentos metodológicos do Percurso de Estudos e Pesquisas (PEP) parecem viáveis no trabalho com a formação continuada, pois segundo Chevallard (2009) essa opção metodológica concerne às praxeologias de investigação, colocadas em jogo em um domínio dado ou em uma pesquisa específica e ressalta que o trabalho coletivo sobre praxeologias de investigação em didática se faz necessário para combater os efeitos dos caminhos maquinalmente trilhados.

\section{Referências}

ALTET, M. PAQUAY, L. PERRENOUD, P. As competências do professor profissional: entre conhecimentos, esquemas de ação e adaptação, saber analisar. Formando professores profissionais: Quais estratégias? Quais competências? 2a ed. Porto Alegre, RS: Artmed Editora, 2001. p. 23-35.

ANDRADE, R. C. D. A Noção de Tarefa Fundamental Como Dispositivo Didático Para Um Percurso De Formação De Professores: o caso da Geometria Analítica. Universidade Federal do Pará, Instituto de Educação Matemática e Científica, Programa de Pós-Graduação em Educação em Ciências e Matemáticas. Tese. Belém, 2012.

\footnotetext{
${ }^{8}$ A participante se refere ao conceito de polígono apresentado.
} 
ALMOULOUD, S. MANRIQUE, A. L. SILVA, M. J. F. CAMPOS, T.M.M. A geometria no ensino fundamental: reflexões sobre uma experiência de formação envolvendo professores e alunos, 2004, p. 94-108. Disponível em: http://www.scielo.br/pdf/rbedu/n27/n27a06.pdf. Acesso em janeiro de 2017.

BOSH, M. GASCÓN, J. Fundamentación antropológica de las organizaciones didáticas: de los "talleres de prácticas matemáticas" a los "recorridos de estudio e investigación. En A. Bronner, M. Larguier, M. Artaud, M. Bosch, Y. Chevallard, G. Cirade \& C. Ladage (Eds.) Diffuser les mathématiques (et les autres savoirs) comme outils de connaissance et d'action (pp. 49-85), Montpellier, Francia: IUFM de I'Académie de Montpellier. 2010. Disponível em site http://www.atd-tad.org/documentos/bosch-m-gascon-j-2010-fundamentacionantropologica-de-las-organizaciones-didacticas-de-los-talleres-de-practicas-matematicasa-los-recorridos-de-estudio-e-investig/. Acesso em janeiro de 2017.

BOSH, M. CHEVALLARD, Y. La sensibilité de l'activité mathématique aux ostensifs. Objet d'étude et problematique. Recherches en Didactique des Mathématiques. Grenoble: La Pensée Sauvage-Éditions, v.19, $n^{\circ} 1, \quad$ p. 77 - 124, 1999. Disponível em site http://yves.chevallard.free.fr/spip/spip/article.php3?id_article=35. Acesso em janeiro de 2017, com paginação de $1-37$.

CHEVALLARD, Y. Analyse des pratiques enseignantes et didactique des mathématiques: l'approche anthropologique. Juillet 1998. Cours donné à I'université d'étéAnalyse des pratiques enseignantes et didactique des mathématiques, La Rochelle, 4-11 juillet 1998; paru dans les actes de cette université d"été, IREM de Clermont-Ferrand, p. 91-120. Disponível em http://yves.chevallard.free.fr/spip/spip/article.php3?id_article=27. Acesso em janeiro de 2017, com paginação de 1-29.

Organizer L'étude. 3. Ecologie \& regulation. Actes de la 11 École d'Été de Didactique des Mathématiques. France: La Pensée Sauvage. 2002. Disponível em: http://yves.chevallard.free.fr/spip/spip/article.php3?id_article=53. Acesso em janeiro de 2017, com paginação de 1-22.

La notion d'ingénierie didactique, un concept à refonder; Clermont-Ferrand, 16-23 août 2009. Disponível em http://yves.chevallard.free.fr. Acesso em janeiro de 2017.

Teaching Mathematics in Tomorrow's Society: A Case for an Oncoming Counter Paradigm. Texto publicado nos anais do ICMI 12 p. 173-187, 2012.

BOSCH, Marianna; GASCON, Josep. Estudar Matemáticas: O elo perdido entre o ensino e a aprendizagem. Porto Alegre: Artmed, 2001.

GASCON, Josep. La necesidad de utilizar modelos en didáctica de las matemáticas. Educ. Mat. Pesqui., São Paulo, v.5, n.2, pp. 11-37, 2003.

LUCAS, C. O. Una posible <razón de ser> del cálculo diferencial elemental em el ámbito de la modelización funcional. Departamento de Matemática Aplicada I. Programa de doctorado Técnicas Matemáticas Avanzadas y sus Aplicaciones. Vigo, 2015.

LEIVAS, J. C. P. Educação Geométrica: Reflexões sobre ensino e aprendizagem em geometria. EMR-RS - ANO 13 - 2012 - número 13 - v.1 - pp. 9 a 16.

LINDQUIST, M. M.; SHULTE, A. (Org.). Aprendendo e ensinando geometria. São Paulo: Editora Atual, 1994. 
LORENZATO, S. Por que não ensinar geometria? A Educação Matemática em Revista - ano III - nº 4 - Publicação da Sociedade Brasileira de Educação Matemática, 1995.

MIZUKAMI, M. G. N. Escola e aprendizagem da docência: processos de investigação e formação. São Carlos - EduUFSCAR, 2002.

NUNES, C. B. O Processo Ensino-Aprendizagem-Avaliação de Geometria através da Resolução de Problemas: perspectivas didático-matemáticas na formação inicial de professores de matemática. Tese de Doutorado, Universidade Estadual Paulista (UNESP), Campus Rio Claro, 2010.

PAIS, L. C. Ensinar e aprender Matemática. Belo Horizonte: Autêntica, 2006.

PAVANELLO, R. M. O abandono do ensino da Geometria no Brasil: causas e consequências. Revista Zetetiké, ano I-n¹/1993.

PERRENOUD. P. As competências para ensinar no século XXI: a formação dos professores e o desafio da avaliação. Porto Alegre, Artmed editora, 2002

RUIZ, A.O. La Formación Matemático-Didáctica Del Profesorado De Secundaria. De Las Matemáticas Por Enseñar A Las Matemáticas Para La Enseñanza. Universidad Autonoma de Madrid. Facultad de Formación de Profesorado Y Educación Departamento de Didácticas Específicas. Madrid, 2015. 